\title{
Predicting fatigue crack growth life for cold-worked holes based on existing closed-form residual stress models
}

\author{
Z. Wang ${ }^{\text {a }}$ \& X. Zhang ${ }^{\mathrm{b}^{*}}$ \\ ${ }^{a}$ Beijing Aeronautical Technology Institute, Beijing, 100076, P R China \\ ${ }^{\mathrm{b}}$ School of Engineering, Cranfield University, Bedford, MK43 OAL, UK
}

\begin{abstract}
This paper studies the capability of four closed-form solutions for calculating cold expansion-induced residual stresses. The aim is to check whether these models are able to provide accurate solutions of residual stresses for three aerospace grade aluminium alloys of medium thickness so that fatigue life can be estimated using these residual stress models without going to the formidable finite element analysis. Based on these studies, crack growth lives for three different kinds of specimens are predicted by the AFGROW computer program and compared with experimental tests. Factors affecting the capability of these closed-form solutions are examined, and modifications to these models based on the fatigue tests and parametric studies are suggested. The study demonstrates that good prediction of crack growth life can be obtained if a suitable closed-form model is used.
\end{abstract}

Keywords: cold expansion, residual stress, closed-form models, fatigue crack growth, fatigue life prediction.

\section{Nomenclature}

$a_{i} \quad$ initial crack length

$\beta \quad$ Bauschinger effect parameter

$\sigma_{y} \quad$ yield stress in monotonic loading

$\mathrm{Cx}$ cold expansion, or cold expanded

NCW non-coldworked, or plain (specimen)

Fl life prediction ratio (i.e. predicted life / test life)

LIF life improvement factor (i.e. life of cold-worked specimen/life of plain specimen)

\section{Introduction}

The A wide variety of approaches have been developed for predicting fatigue crack growth life for coldworked fastener holes [1-16]. The determination of the residual stress distribution around a cold-worked hole is an indispensable prerequisite for the life prediction process, because the residual tangential stress distribution introduced by coldworking is the main reason for fatigue life extension of the part considered. Various techniques have been developed and used to determine the residual stress distribution; these could be divided into three groups: experimental, numerical and analytical approaches.

The experimental techniques include the X-ray diffraction, neutron diffraction, Sach's cutting method, photo-elastic and optical strain measurement. In general accurate results can be achieved by using the experimental techniques as demonstrated by many successful examples [2-3, 7, 10, 17-24].

The numerical approach typically employs the finite element methods (FEM), which have been shown to be efficient for determining the residual stress distributions especially for the mid-thickness range, i.e. neither plane-stress nor plane-strain conditions [2, 7-8, 11, 21, 25-27]. FEM can also deal with material's non-linearity behaviour incurred by cold expansion process.

\footnotetext{
* Corresponding author. Fax: +44 1234758203.

Email address: xiang.zhang@,cranfield.ac.uk (X. Zhang).
} 
Closed-form solutions are usually obtained by analytical techniques. Compared with the numerical or experimental techniques, the closed-form theory often provides a simpler and faster method to acquire the residual stress distribution, because neither special equipment nor tedious calculation is needed in the analytical techniques. And more importantly, relatively good results can be obtained, if a solution is obtained based on adequate assumptions and theory. With the development of the cold-expansion technology, a number of such models have been developed such as those developed by Hsu-Forman [28], Rich-Impellizzeri [1], Chang [3], Ball [6-7] and many others [9, 29-31]. The accuracy of these published close-form models have been verified directly by either experimental measurements or numerical calculations or indirectly by fatigue life results. Comparing to the efforts in FEM or experimental measurement, these close-form models are simpler to use in assessing the beneficial effect of cold expansion. They can be very useful when combined with a computer program for fatigue crack growth life prediction, which is especially helpful at the component design stage.

While good agreement between fatigue test result and predicted lives was found by some researchers using the closed-form models [1, 3-4, 6-7, 9-10], disagreements were also experienced by many others [17-21, 23-24]. The present study aims at examining four popular analytical residual stress models and checking the predicted lives against experimental data. The main objectives are:

(a) To determine the residual tangential stress distribution for a coldworked hole by selected models;

(b) To predict crack growth life by using the AFGROW computer program with input of residual stress distributions determined by the closed-form models;

(c) To evaluate the accuracy of each closed-form model by comparing the predicted crack growth life with experimental results.

\section{Review of four closed-form residual stress models}

Four closed-form solutions are selected for this study, i.e. two plane-stress models by Hsu-Forman [28] and Ball [6], and two plane-strain models by Rich-Impellizzeri [1] and Chang [3]. These models are briefly reviewed below and summarized in Table 1.

Table 1 . Theoretical assumptions made by different residual stress models.

\begin{tabular}{|l|l|l|l|l|l|}
\hline \multicolumn{1}{|c|}{ Model } & Yield Criterion & Stress state & Deformation & Unloading & Mandrel \\
\hline Hsu-Forman [28] & Mises-Hencky & Plane-stress & Elasto-plastic & Elastic & \\
\hline Ball [6] & Mises-Hencky & Plane stress & Elasto-plastic & Elasto-plastic & \\
\hline Chang [3] & Mises-Hencky & Plane-strain & Perfect-plastic & Elastic & Elastic \\
\hline Rich-Impellizzeri [1] & Mises-Hencky & Plane-strain & Elasto-plastic & Elastic & Elastic \\
\hline
\end{tabular}

The common issue among these solutions is how to model the reversed loading (or unloading) due to the mandrel removal. The notion that the yield limit of metals in reversed loading can be different from that in monotonic loading was first proposed by Bauschinger in 1886. For most engineering alloys, the reverse yield stress $\left(\sigma_{r y}\right)$ is a fraction of the tensile yield stress $\left(\sigma_{y}\right)$; this is the so-called Bauschinger or kinematic hardening effect. Assuming a linear hardening, this effect may be demonstrated for a one-dimensional problem [32]. The yielding in tension will lower the reverse yield strength so that: 


$$
(\sigma-\alpha)= \pm \sigma_{y}
$$

where $\alpha$ is the "kinematic shift" of the centre of the yield surface. As a result of this shift, with the initial yield limit $\sigma_{y}$ being fixed, the reverse yield stress decreases and the uniaxial stress $\sigma$ "hardens". In many studies, the shift of the yield surface centre is defined by:

$$
d \alpha=\beta d \varepsilon^{p} \quad(0 \leq \beta \leq 1)
$$

where $\beta$ is a Bauschinger effect related parameter; it depends on the material type, stress state and the magnitude of applied plastic strain. $\beta=0$ simulates isotropic hardening; $\beta=1$ mimics kinematic hardening. For most engineering alloys mixed hardening describes cyclic loading condition better, therefore $0<\beta<1$ for cyclic plasticity analysis.

\subsection{Models based on plane-stress theory}

The Hsu-Forman model [28] was developed by extending the Nadai theory [29] taking account of work hardening effect. The main assumptions were: a) material behavior followed the Ramberg-Osgood relationship; b) yielding was governed by the Mises-Hencky criterion; c) elastic unloading for mandrel removal, hence no reverse yielding.

The Ball's model [6-7] is an extension of the Hsu-Forman theory by including elastic-plastic unloading and, therefore, creating a reverse yielded zone. In the Hsu-Forman model, Budiansky's solution [33] was only used for the loading step, but in Ball's model it was applied for both loading and unloading steps of the coldworking process to generalize the solution and to include any potential reverse yielding. Parameter $\beta$ was introduced to account for the Bauschinger effect. Ball and Lowry evaluated their theory against some x-ray diffraction measurements for a $6.35 \mathrm{~mm}$ thick $2124-\mathrm{T} 851$ aluminium specimen [7], which showed good agreement. They verified the model further by comparing the predicted fatigue life with the fatigue test results; good agreement was achieved.

\subsection{Models based on plane-strain theory}

The Rich-Impellizzeri model [1] is a modification of the elasto-plastic solution of Sachs [34] by including the elastic deformation of the mandrel. The model also assumed elastic unloading following the mandrel removal. The authors validated their theory against some test results for two alloys.

Chang's model was developed based on the elasto-plastic solution of a pressurized thick-walled cylinder of Sachs [34]. It assumed perfectly plastic material, plane-strain condition under uniform pressure at the hole edge, and Misses-Hencky yield criterion. Residual stress distribution was computed for a $12.7 \mathrm{~mm}$ thick 2024-T851 aluminium plate with a coldworked hole and then used for predicting fatigue crack growth in the plate. Good correlation with test data was obtained.

\subsection{Residual stress calculation}

Residual stress distributions described by the four models were calculated for a simple dog-bone specimen with a coldworked hole in the centre as shown in Fig 1. The specimen was made of 2024T351 aluminium alloy having the width of $25 \mathrm{~mm}$, thickness of $6 \mathrm{~mm}$ and hole diameter of $6.35 \mathrm{~mm}$. In this study, the original Rich-Impellizzeri and Ball's models were modified to account for the Bauschinger effect for this aluminium alloy. For the modified Rich-Impellizzeri model a reverse yield stress being $60 \%$ of that in tension was assumed. For Ball's model kinematic hardening $(\beta=1)$ was assumed. For this alloy the work hardening index in the original Budiansky's relation [33], $n$, was assumed to be equal to 2.7 for the Hsu-Forman and Ball models. The differences in the theoretical predictions simply reflect the theoretical treatment of residual stresses adopted by different researchers.

Figure 1 also shows that the residual tangential stress distributions can be divided into three regions (A, $\mathrm{B}$ and $\mathrm{C})$. Region $\mathrm{A}$ is at the vicinity of hole edge having compressive tangential stress and a reverse 
yield zone, region $\mathrm{B}$ is transitional between compression and tension with elasto-plastic stresses, and region $\mathrm{C}$ is the elastic region.

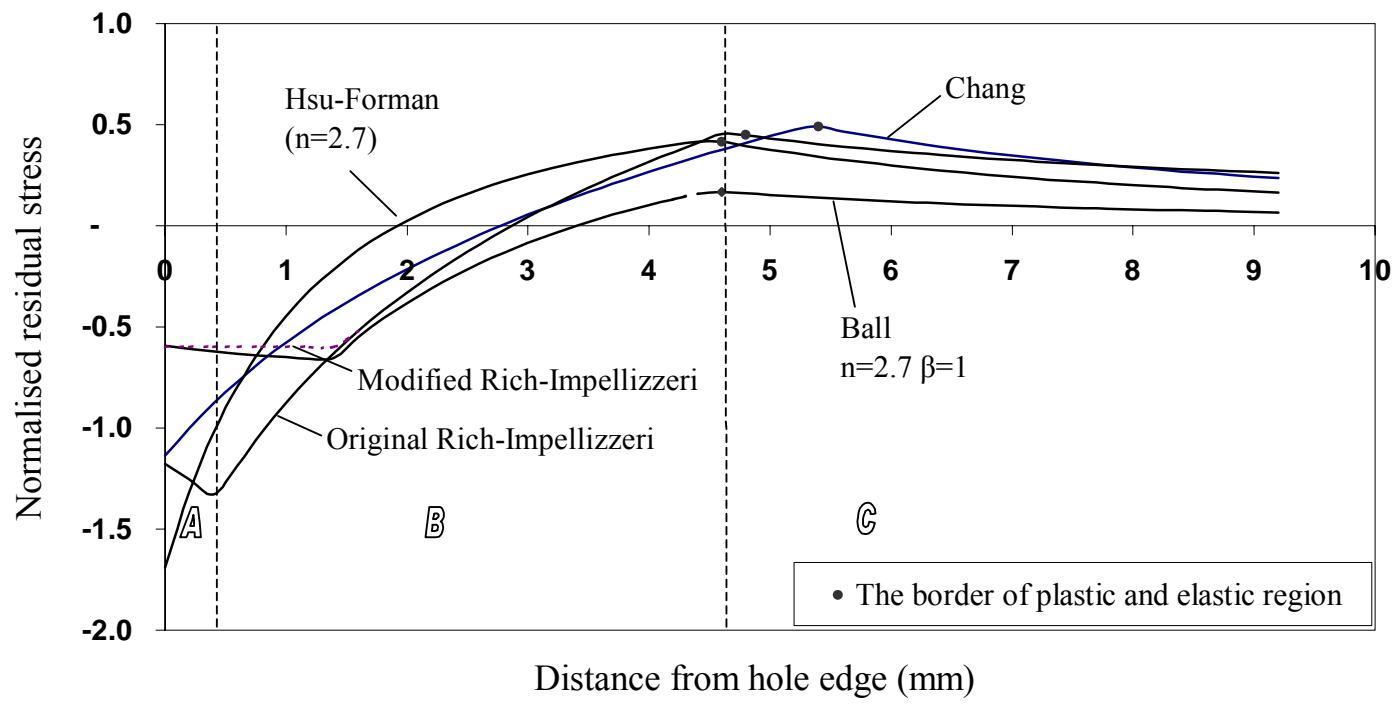

Fig. 1 Residual stress distributions calculated by four different closed-form models.

\section{Prediction of crack growth lives and discussion}

\subsection{Life prediction results and validation tests}

Three different specimen geometries were chosen for this study, i.e. specimens A, B and C. The geometrical and testing details are listed in Table 2. As all three specimens are around $6 \mathrm{~mm}$ thick, which fits in neither plane-strain nor plane-stress conditions, they lie in the so-called "transition region". Crack growth lives of the three specimens were predicted by using the above four closed-form residual stress models and the AFGROW computer program [35]. The predicted results, together with the test results, are given in Figs. 2-4, respectively. For specimen A the average fatigue lives to initiate a $0.5 \mathrm{~mm}$ long crack were 5000 flights for plain hole specimens and 7500 flights for coldworked specimens, respectively [36]. Therefore, the initial crack length was set $0.5 \mathrm{~mm}$ for the crack growth life prediction for specimen A (Fig. 2). Four specimens' test results were reported in Fig. 2: T07 and T09 for plain hole tests, and T05 and T06 for coldworked holes. Crack length were constantly measured and for most tests, $0.5 \mathrm{~mm}$ long cracks were found with high confidence [36], but cracks shorter than this length (T06R) were also found and reported in Fig. 2.

According to Poolsuk \& Sharpe [18], when the plate thickness and the hole diameter are about the same, the plane-strain theory gives better prediction. Of the four residual stress models used in this study, RichImpellizzeri and Chang's models are based on the plane-strain theory, so it was expected that they provide realistic residual stresses that should lead to good fatigue life prediction. This is demonstrated in the tests A and B (Figs. 2-3): the modified Rich-Impellizzeri model predicts the lower boundary while the Chang's model estimated high boundary of fatigue lives (Fig. 2); both predictions fall into the acceptable range. Hsu-Forman and Ball's models are based on the plane-stress theory, and they both overestimated the fatigue crack growth life for specimen A. Hsu-Forman model overestimated the fatigue life significantly; between 2-4 times longer lives were predicted, so that the prediction curve is out of the scale of Fig. 2. 
However, for specimens B and C, Hsu-Forman model underestimated the fatigue crack growth lives. Life prediction is influenced by many factors. Apart from the Bauschinger effect, material's hardening index, residual stress profiles and initial crack length all play important roles. A parametric study on these factors is presented in Section 3.2. For all three tests Ball's model could give good predictions when set $\beta=1$ (Fig. 2-4). However, for 2024-T351 alloy, both theoretical and experimental works suggest that the cyclic stress-strain behaviour is better represented by a mixed hardening rule. However, when using a mixed hardening rule $(0<\beta<1)$ the life was overestimated by the Ball's model suggesting there are other influential factors. Details are discussed in the next section.

Table 2. Main parameters used in the three specimens for fatigue tests ${ }^{\mathrm{a}}$.

\begin{tabular}{|l|l|l|l|l|l|l|l|l|l|}
\hline Specimen & $\begin{array}{l}\text { Data } \\
\text { Source }\end{array}$ & $\begin{array}{l}\text { Expansion } \\
\text { Ratio (\%) }\end{array}$ & Material & $\begin{array}{l}\text { Thickness } \\
(\mathrm{mm})\end{array}$ & $\begin{array}{l}\text { Width } \\
(\mathrm{mm})\end{array}$ & $\begin{array}{l}\text { Hole } \\
\text { Diameter } \\
(\mathrm{mm})\end{array}$ & $\begin{array}{l}\text { Initial crack } \\
(\mathrm{mm})\end{array}$ & $\begin{array}{l}\text { Final crack } \\
(\mathrm{mm})\end{array}$ & $\begin{array}{l}\text { Loading } \\
\text { Spectrum }\end{array}$ \\
\hline $\mathrm{A}$ & {$[36]$} & 3.7 & $\begin{array}{l}2024- \\
\text { T351 }\end{array}$ & 6.0 & 25 & 6.35 & 0.5 & 2.4 & FALSTAFF \\
\hline B & {$[4]$} & 5.1 & $\begin{array}{l}7075- \\
\text { T651 }\end{array}$ & 6.4 & 51 & 6.63 & 1.9 & 9.0 & $\begin{array}{l}\text { Constant } \\
\text { amplitude } \\
(\mathrm{R}=0.05)\end{array}$ \\
\hline $\mathrm{C}$ & {$[39]$} & 3.4 & $\begin{array}{l}7075- \\
\text { T76511 }\end{array}$ & 6.4 & 89 & 7.87 & 1.6 & 10.0 & $\begin{array}{l}\text { Constant } \\
\text { amplitude } \\
(\mathrm{R}=0.1)\end{array}$ \\
\hline
\end{tabular}

a. All specimens had the dog-bone shape with an open-hole in middle of the specimen.

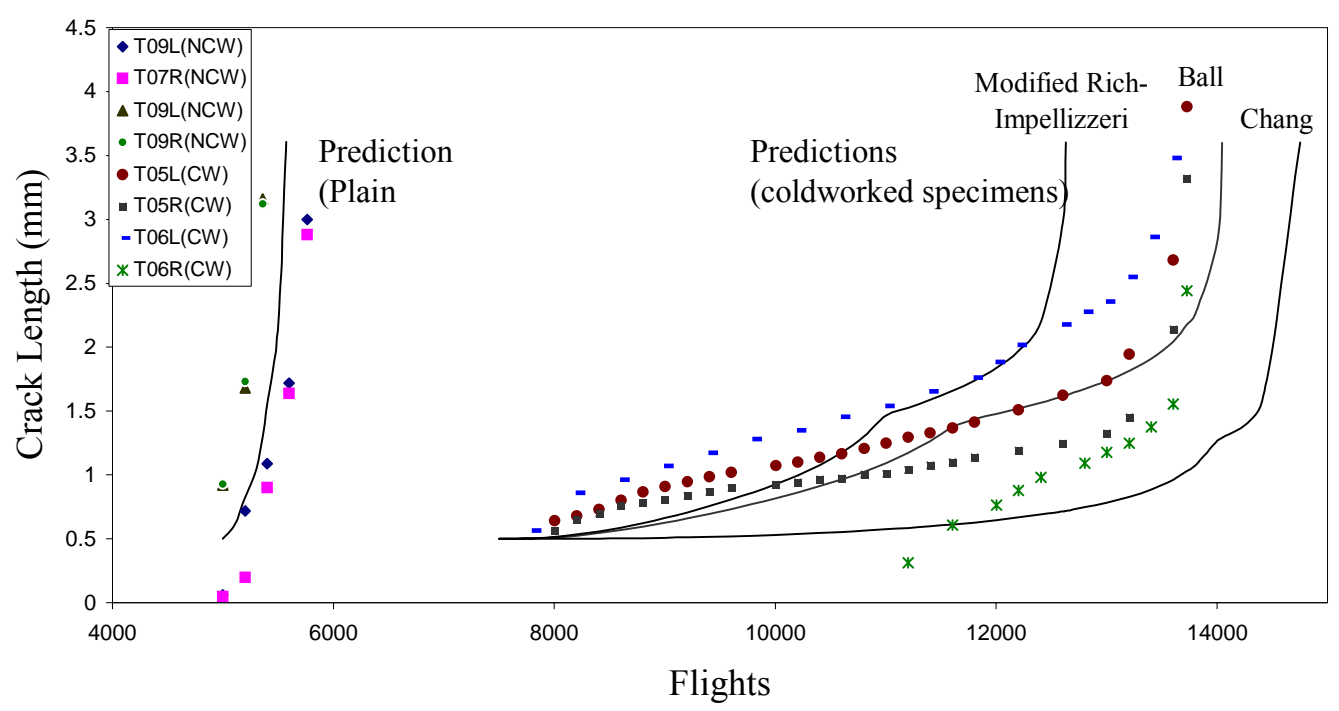

Fig. 2 Life prediction results for specimen A under FALSTAFF spectrum loading. Predictions in smooth lines; scatters symbols for experimental data for specimens T05-T09. Symbols L and R signify the left and right hand sides of the hole, and $\mathrm{CW}$ and $\mathrm{NCW}$ represent coldworked and non-coldworked conditions.

Test specimen A was subjected to spectrum loading. Crack growth life under spectrum loading is considerably different from that under constant amplitude testing. The most important load sequence effect is the crack growth rate retardation effect due to intermittently applied high tensile load cycles. In 
this work, the crack closure model available in the AFGROW package was used to account for the overload retardation effect.

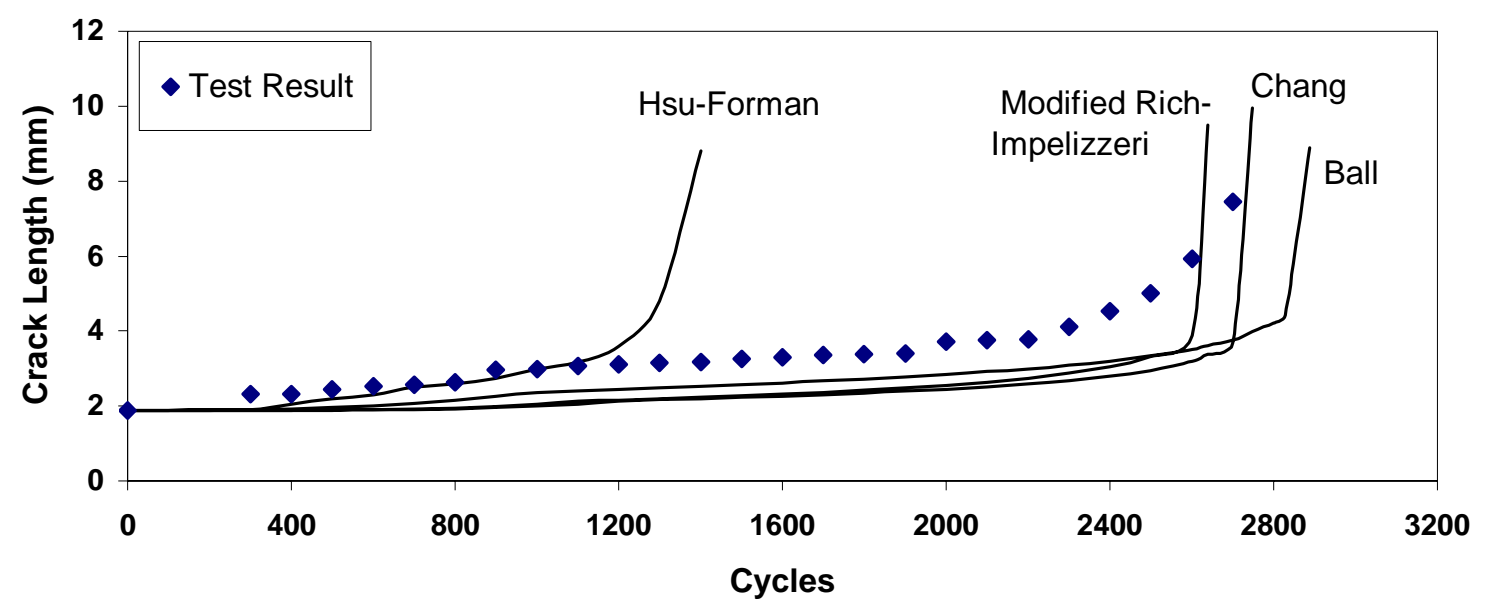

Fig. 3 Life prediction results for specimen B under constant amplitude loading. Predictions in smooth lines; experimental data by scatters symbols.

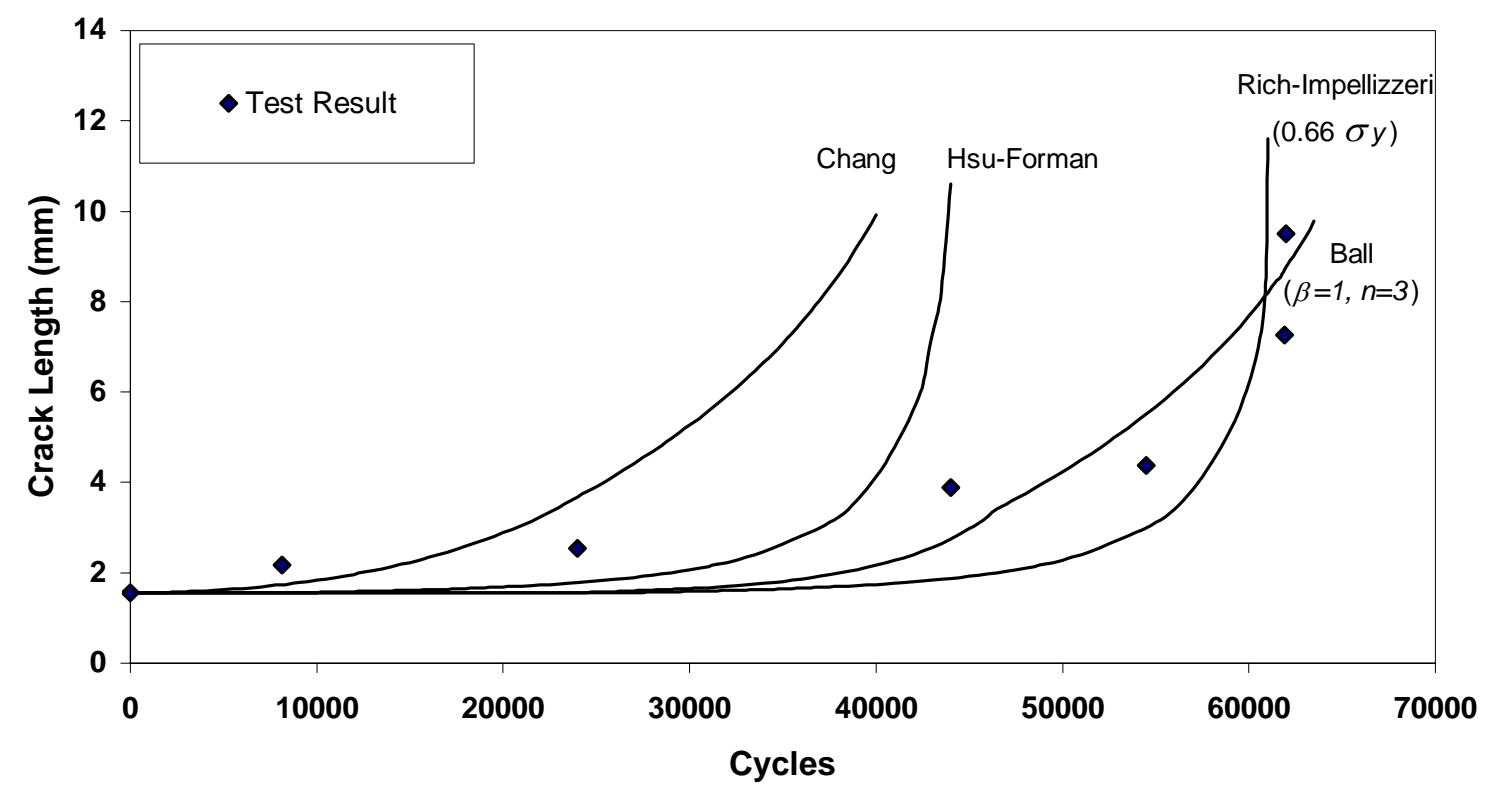

Fig. 4 Life prediction results for specimen $\mathrm{C}$ under constant amplitude loading. Predictions in smooth lines; experimental data by scatters symbols 


\subsection{Discussion on influential factors}

\subsubsection{The strain hardening index $n$}

In Hsu-Forman and Ball's models, the stress-strain relationship is expressed by the Budiansky's relation [33]:

$$
\varepsilon=\frac{\sigma}{E} \quad\left(\sigma<\sigma_{y}\right) ; \quad \varepsilon=\frac{\sigma}{E}\left(\frac{\sigma}{\sigma_{y}}\right)^{n-1} \quad\left(\sigma>\sigma_{y}\right)
$$

where $n$ is the parameter related to strain hardening and thus defining the shape of the uniaxial monotonic stress-train curve after yielding. However, most engineering stress-strain curves are usually expressed by the Ramberg-Osgood relation, which can be found in many textbooks on metal fatigue, such as [37-38]. In an analogous fashion, the cyclic stable stress-stain response is characterized by the same relationship [37]:

$$
\varepsilon_{a}=\frac{\sigma_{a}}{E}+\left(\frac{\sigma_{a}}{A}\right)^{1 / s}
$$

where, $\varepsilon_{\mathrm{a}}=\Delta \varepsilon / 2$ is the strain amplitude, $\sigma_{\mathrm{a}}=\Delta \sigma / 2$ the stress amplitude, $E$ elastic modulus, $A$ and $s$ are constants for a given material, and $\mathrm{s}$ is the cyclic strain hardening exponent. The values of $A$ and $s$ have been given in [37] for some materials, but data are not available for the 2024-T351. We therefore used following formula for 2024-T351 because the constants are available [38]:

$$
\varepsilon=\frac{\sigma}{E}+0.002\left(\frac{\sigma}{420}\right)^{9.5}
$$

Fitting the curve by Eq. 5 to the curves calculated by Eq. 3, the value of $n$ was 2.7 for 2024-T351 (specimen A). For the materials used for specimens $\mathrm{B}$ and $\mathrm{C}$, the index are close to $n=2$ and $n=3$, respectively.

\subsubsection{The Bauschinger effect}

As mentioned before, the Bauschinger parameter $\beta$ was introduced in the unloading formula of the Ball's model, which significantly influences the shape and the magnitude of the residual compressive stresses near the hole edge (region A in Fig. 1), hence affects the crack growth life. For specimen A made of 2024-T351 alloy, variations of the residual stress distribution and the corresponding fatigue life ratio $\mathrm{Fl}$ (predicted life / test life) with different $\beta$ values are given in Fig 5, which shows that $\beta$ value directly influences the point where the reverse yielding begins during the unloading step. For $\beta$ $=0$ (isotropic hardening), the reverse yield zone is smaller, but the magnitude of the compressive stresses in region A is larger. Since the reverse yield zone is smaller than the initial crack length $(0.5$ $\mathrm{mm}$ ), the predicted life and $\mathrm{Fl}$ are longer compared to the predictions based on $\beta>0.4$. The predicted life is the lowest and most close to test result $(F l=1.52)$ when $\beta=1$ (kinematic hardening). Therefore assuming kinematic hardening in Ball's original model works very well for this material and test. The difference of $F l$ values between $\beta=0$ and $\beta=1$ is more than 10 times.

The Rich-Impellizzeri model was also modified to account for the Bauschinger effect. In this study, the residual compressive stresses near the hole edge were assumed to be constant at a fraction of the tensile yield stress, i.e. $\sigma_{r y}=c \sigma_{y}, c \leq 1$. The original Rich-Impellizzeri model predicts variable residual compressive stresses near the hole edge and the magnitude of the maximum compressive stress is larger than the tensile yield stress, e.g. $c=1.1-1.2$ for test case A. Fig. 6 shows the predicted residual tangential stress distributions with different $c$ values and predicted fatigue lives. As $c$ approaches 1 the hardening rule becomes increasingly isotropic, consequently the reverse yield zone is smaller and the magnitude of compressive residual stress increases. Fig. 6 also shows that the mixed hardening 
behavior $\left(\sigma_{r y}=0.6-0.7 \sigma_{y}\right)$ gives the best prediction of fatigue crack growth life. The test result was based on specimen A (Table 1).

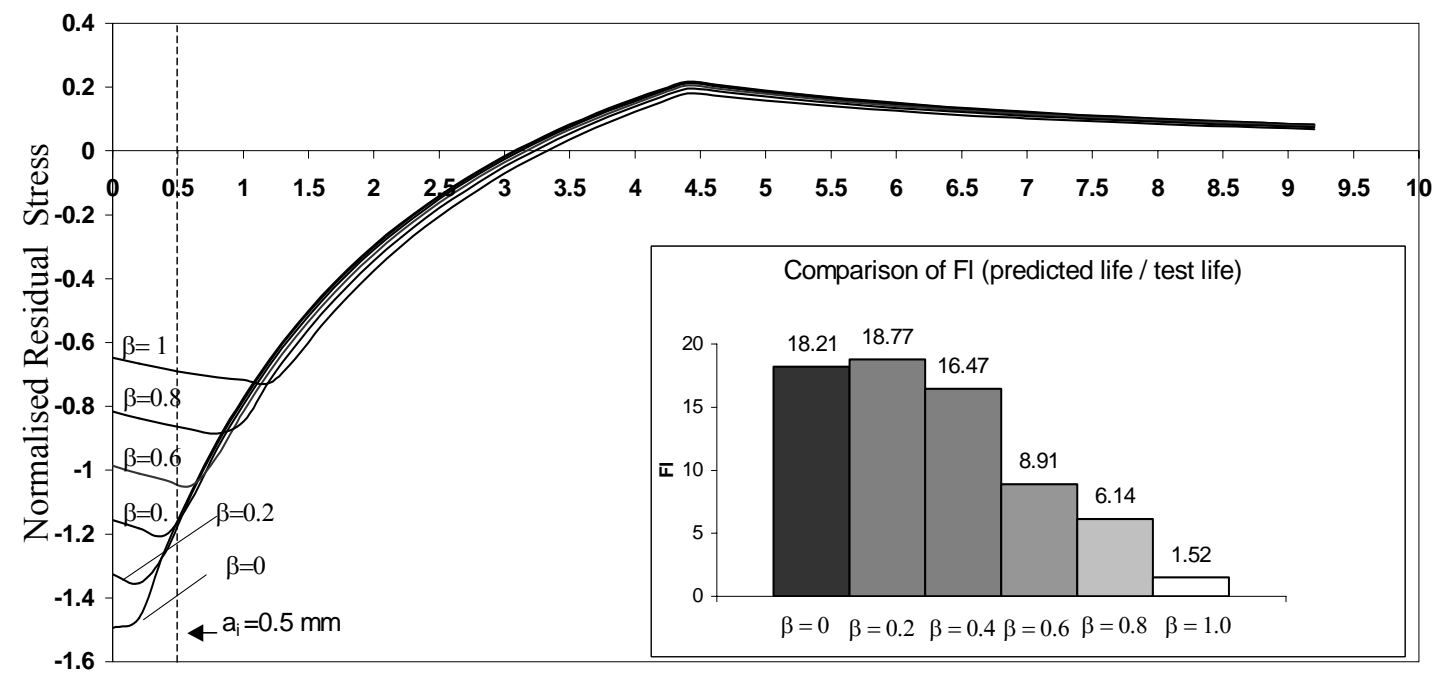

Distance from hole edge $(\mathrm{mm})$

Fig. 5 Residual stress distributions calculated by Ball's model with Bauschinger effect (controlled by $\beta$ ) and life prediction results in terms of life prediction ratios $(F l)$.

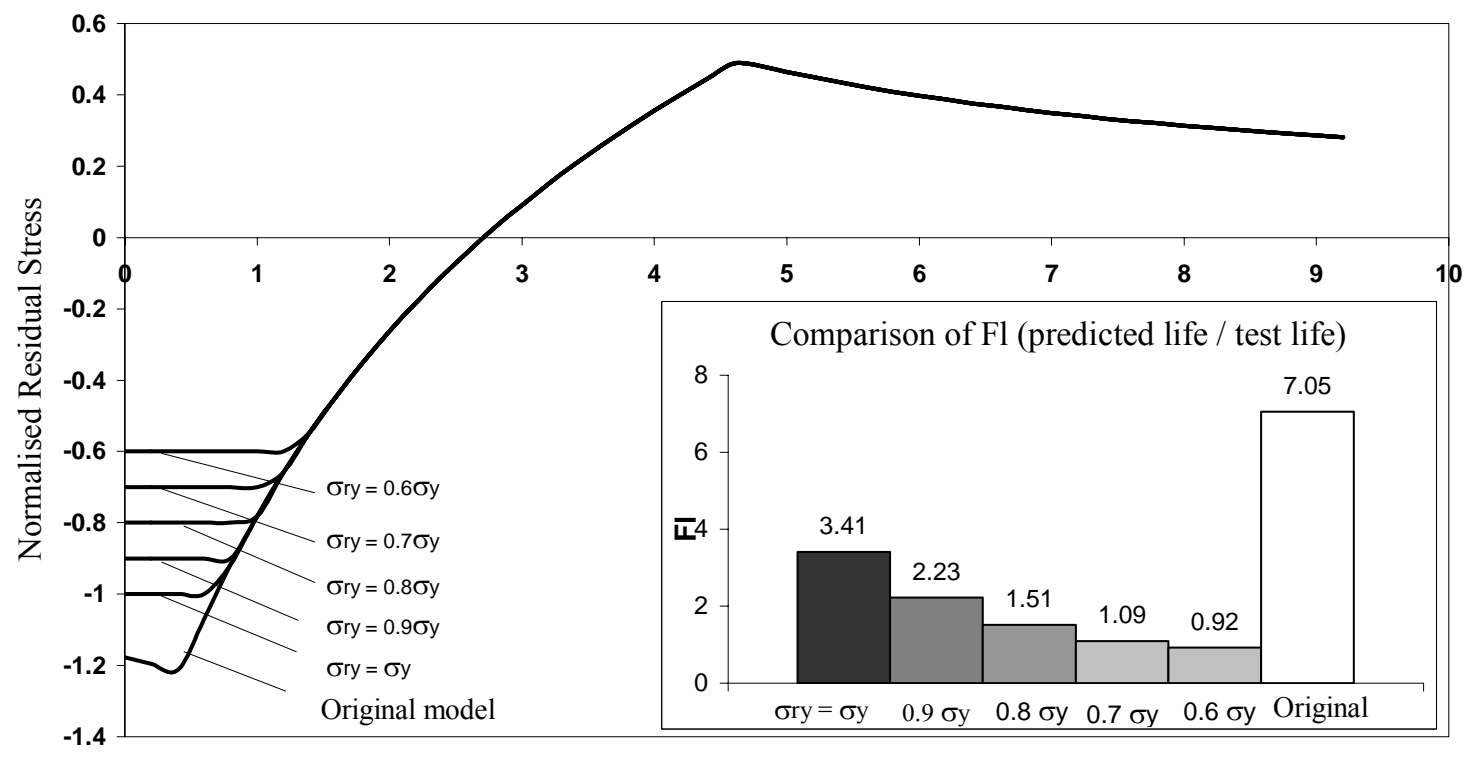

Distance from hole edge $(\mathrm{mm})$

Fig. 6 Residual stress distributions calculated by Rich-Impellizzeri model with Bauschinger effect (controlled by reverse yield stress) and life prediction ratios $(F l)$. 


\subsubsection{Effect of residual stress profile and initial crack length}

Although the two residual stress distributions determined by the Ball and the Chang's models are different (Fig. 1), the life prediction results are similar and both models predicted the final lives very well (Fig. 2). However, one can see the difference between these two models from the corresponding crack growth life curves, which show that the curves predicted by the Chang's model can only fit the test results in the final stage, while the predictions by Ball's model match almost entire crack growth history. The reason for using different residual stress distributions resulting in similar Fl values is that the Fl is calculated by summing of the life accumulations from different stages. Compared with the Ball model, the Chang's model gives more life contribution in region A but less contribution in region B, but the total life sum might be the same. Therefore, the residual stress distribution determined by the Ball's model $(\beta=1)$ is the closest one to the actual residual stress situations for the three specimens studied. This statement is supported by the experiment results in [6-7, 10,21]. The results in [21], which were obtained by the x-ray diffraction, are more persuadable, because the specimens in [21] were made of same material, having similar thickness, hole diameter and cold-expansion ratio as the specimen A of this study.

When a crack grows into the residual stress region C (Fig. 1), the crack has entered the so called "fast crack growth" region. Therefore, the accuracy in residual stress values and distribution in regions A and $\mathrm{B}$ are more important for life prediction than region $\mathrm{C}$. The life proportion from growth in region $\mathrm{A}$ is also dependent upon the initial crack length. The longer the initial crack length, the less the contribution will be made by that region. For example, as shown in Fig.1, compared with the other models, the HsuForman model overestimated the compressive stresses in the A region and underestimated the stresses in B. If an initial crack length $\left(a_{i}\right)$ is longer compared to the length of region A, the life predicted by HsuForman model will be shorter (than test results). In the present investigation, fatigue lives were underestimated based on the Hsu-Forman model for specimens B and C, because long initial crack lengths were chosen (1.5 and $1.9 \mathrm{~mm}$, respectively). Similarly, life was overestimated for specimen A by the Hsu-Forman model because a much shorter initial crack length of $0.5 \mathrm{~mm}$ was chosen. However when the initial crack length of specimen A was assumed to be $1 \mathrm{~mm}$, the predicted life was greatly reduced compared to the corresponding test result from $1 \mathrm{~mm}$ crack to final failure.

It should be noted that all these residual stress models are developed for cold expanded or interference fitted holes assuming there are no cracks. However, the life predictions made in this study (and many others in the literature) assumed the residual stress distribution remained the same after initiation of a small crack. This assumption is not correct. Ozdemir \& Edwards [40] found that the residual tangential stress profile near the hole would decay due to the initiation and growth of short fatigue cracks; both fatigue loading cycles and initiation of a small crack will affect the residual stress profile. Therefore, current life prediction exercises based on close-form models will only provide approximate fatigue lifetimes.

\section{Conclusions}

Good prediction of fatigue crack growth life can be achieved if a suitable closed-form model is used for determining the residual tangential stress distribution. For specimens with thickness of around $6 \mathrm{~mm}$, some modifications are necessary to the four closed-form residual stress models reviewed, which deal with either plane-stress or plane-strain conditions. Among the four closed-form models studied in this paper, attention should be paid to the parameters associated with work hardening and the Bauschinger effect.

Life prediction for cold worked holes is also very sensitive to the initial crack length. This is because that the beneficial residual stresses only exist in the early stage of crack growth. 
The Hsu-Forman model is not suitable for specimens with thickness around $6 \mathrm{~mm}$, because it gives unrealistic residual compressive stresses under plane stress condition.

Ball's model works very well for the material and tests reviewed in this work if assuming kinematic hardening behaviour.

The Rich-Impellizzeri model over-estimates the residual compressive stresses near the hole edge, but gives good description for the stresses away from hole edge. Therefore, with suitable modification by incorporating the Bauschinger effect, the accuracy in life prediction can be improved.

\section{Acknowledgements}

ZW gratefully acknowledges the support from the China Scholarship Council. The work was carried out at the Cranfield University.

\section{References}

1. Rich DL, Impellizzeri LF. Fatigue analysis of cold-worked and interference fit fastener holes. Cyclic Stress-Strain and Plastic Deformation Aspect of Fatigue Crack Growth, ASTM STP 637, Amer. Soc. for Test and Mat. 1977: 153-175.

2. Cook R, Holdway P. Residual stresses induced by hole cold expansion. Computer Methods and Experimental Measurement for Surface Treatment Effects, Computational Mechanics Publications, Great Britain, 1993; 90-100.

3. Chang JB. Prediction of fatigue crack growth at cold-worked fastener holes. J. Aircraft, 1977; 14 : 903-908.

4. Cathey WH, Grandt Jr AF. Fracture mechanics consideration of residual stresses introduced by coldworking fastener holes. J. Engng Materials \& Technology, 1988; 102: 85-91.

5. Grandt Jr AF. Crack face pressure loading of semi-elliptical cracks located along the bore of a hole. Engng Fract Mech, 1981; 14: 843-852.

6. Ball DL. Elastic-plastic stress analysis of cold expanded fastener holes. Fatigue Frat. Engng. Mater. Struct., 1995; 18: 47-63.

7. Ball DL, Lowry DR. Experimental investigation on the effects of cold expansion of fastener holes. Fatigue Fract. Engng. Mater. Struct. 1998; 21: 17-34.

8. Armen H, Levy A, Eidinoff HL. Elastic-plastic behavior of cold-worked holes. J. Aircraft, 1984; 21: 193-201.

9. Clark G. Modelling residual stresses and fatigue crack growth at cold-expanded fastener holes. Fatigue Fract. Engng. Mater. Struct., 1991; 14: 579-589.

10. Su X, Gu M, Yan M. A simplified residual stress model for predicting fatigue crack growth behavior at coldworked fastener holes. Fatigue Fract. Engng. Mater. Struct., 1986; 9: 57-64.

11. Moshier MA, Hillberry BM. The inclusion of compressive residual stress effects in crack growth modelling. Fatigue Fract. Engng. Mater. Struct. 1999; 22: 519-526.

12. Kliman V, Bily M, Prohacka J. Improvement of fatigue performance by cold hole expansion, Part I: Model of fatigue limit improvement. Int J Fatigue, 1993; 15: 93-100.

13. M.Beghini, L.Bertini, E.Vitale. Fatigue crack growth in residual stress fields: experimental results and modelling. Fatigue Fract. Engng. Mater. Struct. 1994; 17: 1433-1444.

14. Pavier MJ, Poussard CGC, Smith DJJ. Effect of residual stress around cold worked holes on fracture under superimposed mechanical load. Eng Fract Mech. 1999; 63: 751-773.

15. Duprat D, Campassens C, Balzano M, Boudet R. Fatigue life prediction of interference fit fastener and cold worked holes. Int. J. Fatigue, 1996; 18: 515-521.

16. Buxbaum O, Huth H. Expansion of cracked fastener holes as a measure for extension of lifetime to repair. Eng Fract Mech. 1987; 28: 689-698.

17. Sharpe WN. Residual strains around coldworked fastener holes. J. Engng Materials \& Tech. 1978; 100: 310-312. 
18. Poolsuk S, Sharpe WN. Measurement of the elastic-plastic boundary around cold-worked fastener holes. Transactions of the ASME, J Applied Mechanics, 1978; 45: 515-520.

19. Link RE, Sanford RJ. Residual strains surrounding split-sleeve cold expanded holes in 7075-T651 aluminium. J Aircraft. 1990; 27: 599-604.

20. Hermann R. Three dimensional stress distribution around cold expanded holes in aluminium alloys. Eng Fract Mech, 1994; 48: 819-835.

21. Priest M, Poussard CG, Pavier MJ, Smith DJ. An assessment of residual-stress measurements around cold-worked holes. Experimental Mechanics, 1995; 361-366.

22. Cloud G. Residual surface strain distribution near fastener holes which are coldworked to various degrees. Wright-Patterson Air Force Base, OH, AFML-TR-78-153, 1978.

23. Cloud G. Measurement of strain fields near coldworked holes. Experimental Mechanics, 1980; 20: 9-16.

24. Edwards L, Ozdemir AT. Effect of residual stress on fatigue life of cold expanded fastener holes. Computer Method and Experimental Measurements for Surface Treatment Effects, Computational Mechanics Publications, Great Britain, 1993; 102-109.

25. Guo W. Elastic-plastic analysis of a finite sheet with a cold-worked hole. Eng Fract Mech. 1993; 45: 857-64.

26. Bernard M, Bai-Quoc T, Burlat M. Effect of re-coldworking on fatigue life enhancement of a fastener hole. Fatigue Fract. Engng. Mater. Struct. 1995; 18: 761-775.

27. Banks-Sills L, Dagani E, Eliasi R, Reinberg E, Schwartzman R. Analysis and testing of surface coldwork procedures applied to notched flat elements. Fatigue Fract. Engng. Mater. Struct. 1994; 17: 1371-1381.

28. Hsu YC, Forman RG. Elastic-plastic analysis of an infinite sheet having a circular hole under pressure. Transactions of the ASME, J Applied Mechanics. 1975: 42: 347-352.

29. Nadai A. Theory of flow and fracture of solids. MCGRAW-HILL, NewYork, 1950.

30. Wang GS. An elastic-plastic solution for a normally loaded center hole in a finite circular body. Int. J. Press-Ves \& Piping, 1988; 33: 269-284.

31. Mangasarian OL. Stresses in the plastic range around a normally loaded circular hole in an infinite sheet. Transactions of the ASME, J Applied Mechanics. 1960; 27: 65-73.

32. MA Crisfield. Non-linear Finite Element Analysis of Solids and Structures, Vol. 1: Essentials, John Wiley \& Sons, 1991 (Chapter 6).

33. Budiansky B. An exact solution to an elastic-plastic stress concentration problem. Prikladnay a Matematika I Physik. 1971; 35: 40-48.

34. Hoffman,O, Sachs,G. Introduction to the Theory of Plasticity for Engineers. MCGRAW-HILL, NewYork, 80-95 (1953).

35. Harter JA. AFGROW Users Guide and Technical Manual. AFRL-VA-WP-1999-3016.

36. Gaerke JG, Zhang X, Wang Z. Life enhancement of fatigue aged fastener holes using cold expansion process, Proc Instn Mech Engrs Part G: J of Aerospace Engng. 2000; 214: 281-293.

37. Suresh, S. Fatigue of Materials, Cambridge University Press, 1991 (Chapter 2).

38. Buch A. Fatigue Strength Calculation. ISBN 0-87849-536-3, Trans Tech Publications, 1988 (p. 177).

39. Toor PM. Cracks emanating from precracked coldworked holes. Eng Fract Mech, 1976; 8: 391-395.

40. Ozdemir AT, Edwards L. Relaxation of residual stresses at cold-worked fastener holes due to fatigue loading. Fatigue Fract. Engng Mater. Struct. 1997; 20: 1443-1451. 